\title{
Summer Doesn't Reverse Freshman Year Body Weight and Fat Gains in Female College Students
}

\author{
Sareen S. Gropper*, ${ }^{* 1}$, Kayla Clary ${ }^{1,2}$, Alisha Gaines ${ }^{1, \#}$, Desiree Wanders ${ }^{1, \dagger}$ and Karla Simmons ${ }^{3}$ \\ ${ }^{I}$ Department of Nutrition, Dietetics, and Hospitality Management, 101 Poultry Science Bldg., Auburn University, AL \\ 36849, USA \\ ${ }^{2}$ Department of Anatomy, Physiology, and Pharmacology, 212 Greene Hall, Auburn University, AL, 36849, USA \\ ${ }^{3}$ Department of Consumer Affairs, 308 Spidle Hall, Auburn University, AL 36849, USA
}

\begin{abstract}
College students, especially females, gain weight their freshman year. Yet, what happens after this first year? This study's purposes were to compare changes and rates of change in weight, body mass index (BMI), body composition (percent body fat, fat mass, fat free mass) and waist circumference between the freshman academic year and the following summer among female college students. Summer weight change also was compared between those who gained versus those who lost weight over the academic year. Participants included 237 females recruited at the beginning of the freshman year. Height and weight were measured using standard anthropometric techniques. Body composition was measured using bioelectrical impedance analysis; waist circumference was measured using a body scanner. Assessments were performed during the freshman (beginning and end) and sophomore (beginning) years. Weight gain for the 237 females during the academic year was $1.4 \mathrm{~kg}$ with an average $0.1 \mathrm{~kg}$ loss over the summer. Rates of change and increases in weight, BMI, body composition, and waist circumference were significantly higher over the academic year than the summer. When only those 162 participants who gained weight over the academic year were considered, academic year weight gain averaged $2.8 \pm 2.3 \mathrm{~kg}$, but only $-0.3 \pm 1.7 \mathrm{~kg}$ were lost over the summer. Weight change was significantly correlated with waist circumference change. Weight gained by college freshmen over the academic year was not lost over the summer. Weight gain was accompanied by unhealthy gains in percent body fat, fat mass, and waist circumference.
\end{abstract}

Keywords: Obesity, weight gain, freshman year, college.

\section{BACKGROUND}

Obesity (and overweight) is a major public health problem affecting about $66 \%$ of adults in the United States [1]. Yet, among the adult population, the prevalence of obesity and overweight increases with each age bracket until age 65 years at which point the prevalence declines [1-5]. For example, the percentage of adults who are overweight or obese in the 18-24 year age bracket is about $44 \%$ [2]. However, in the 25-34 year age bracket, the percentage of adults categorized as overweight or obese jumps to about $63 \%$, and, by 55-64 years, the prevalence is $72 \%$ [2]. Interestingly, the increase in prevalence of overweight and obesity has been shown to be the greatest for the 18-29 year age group, which includes college-aged students [5].

It is well-established that most college students, especially females, gain weight their freshman year [6-29]. Young adults, after graduating high school, typically move away from a "home" and enter a "new college environment".

*Address correspondence to this author at the Department of Nutrition, Dietetics, and Hospitality Management, 101 Poultry Science Bldg., Auburn University, AL, 36849, USA; Tel: 334-844-3271;

E-mail groppss@auburn.edu

"Current address: Department of Nutrition and Hospitality Management, 206 Doster Hall, Box 870158, The University of Alabama, Tuscaloosa, AL 35487, USA

${ }^{\dagger}$ Current address: Vanderbilt University Medical Center, The Vanderbilt Clinic B-802, 1320 22nd Avenue South, Nashville, TN 37232, USA
College freshmen have to develop their own dietary, physical activity, and other lifestyle habits. Some, but not all, studies involving college students, mostly freshmen, have found associations between weight gain and, for example, alcohol consumption, workload, stress, meal consumption at campus dining halls, physical inactivity, and dieting strategies $[7,10,18-22,24,25,30]$. Changes in lifestyle, however, continue to occur throughout the college years. For example, at the end of the first academic year of college (that is, the end of spring semester), most freshmen move out of campus dorms and, for the summer, either move back home with their parents or move into an apartment. Other students who lived off campus during the freshman year may remain in off campus housing or may move back home for the summer. Only one study, conducted in Oklahoma, has examined the effects of summer on changes in body weight and composition in college students after the freshman year; this study found that women gained an additional $0.1 \mathrm{~kg}$ along with increased percent body fat and decreased fat free mass over the summer [29].

The present study extends this work of Hull and coworkers [29] including a larger group of females with body mass indexes both above and below the healthy/normal range (that is $20<25 \mathrm{~kg} / \mathrm{m}^{2}$ ) used by Hull [29] and includes waist circumference measurements. In addition, physical activity behaviors were examined. The main objectives of the present study were to compare changes and rates of changes in weight, body mass index (BMI), percent body fat, fat mass, 
fat free mass, and waist circumference among first year college females between the freshman academic year and the summer after the freshman year. Additionally, the present study also examined summer weight change to determine if participants either lost weight that was gained or gained weight that was lost over the academic year. Differences in summer weight change based on end of the academic year BMI were also examined.

\section{METHODS}

\section{Participants}

Freshmen were recruited to participate in a prospective, observational, longitudinal study during the first four weeks of fall semester in 2007 (cohort 1) and in 2008 (cohort 2). Recruitment was accomplished by email to newly admitted freshmen who attended summer advising sessions at the university. Additionally, oral announcements were made and emails were sent to students enrolled in introductory level courses typically taken by first year students. Participants were excluded if not 17-19 years of age, if married, if they had children, or if they reported an eating disorder.

\section{Study Protocol}

Participants are being followed longitudinally over the next four years. Students were assessed at the beginning of the fall semesters, at the end of the fall semesters (freshman year only), and at the end of the spring semesters. Freshmen received $\$ 25$ and sophomores received $\$ 30$ for participating in the beginning of fall and end of spring semester assessments, and freshmen received $\$ 20$ for the end of fall semester assessment; the initial and end of spring assessments paid more money since participation time was longer. The study was approved by the Institutional Review Board for the Use of Human Subjects in Research at Auburn University. Signed, informed consent was obtained from each participant and from a parent or guardian if the participant was under 19 years of age.

\section{Measures}

Anthropometric measurements, including height, weight, body composition, and waist circumference, were performed as described by Gropper and associates [13]. Briefly, body weight was measured to the nearest $0.1 \mathrm{~kg}$ and height was measured to the nearest half $\mathrm{cm}$ using a digital scale with an attached height rod, respectively (Healthometer, Pelstar, LLC, Model 500KL, Bridgeview, IL). Participants removed shoes, hats, belts, and outer garments, and emptied pockets before being weighed and measured. Subjects were observed to wear similar attire (usually shorts and a t-shirt) at each assessment, making it unlikely that significant differences in clothing weight existed across assessments. BMI was calculated as weight divided by height squared $\left(\mathrm{kg} / \mathrm{m}^{2}\right)$. Body composition was measured using bioelectrical impedance analysis and waist circumference was measured using the NX16 three-dimensional body scanner (TC ${ }^{2}$, Raleigh, NC) as described by Gropper and colleagues [13].

A demographic questionnaire was administered at each assessment to obtain information from participants regarding sex, race/ethnicity, date of birth, state of permanent residence, and location of residence (e.g. on campus residence hall, off campus apartment, trailer, duplex or house, frater- nity/sorority house, or at home with parents) at college and during the summer after the freshman year. Demographic information was also obtained from the Office of Institutional Research and Assessment for all freshmen at Auburn University. Auburn University's 2007 incoming freshman class (from which the subjects of the first cohort were recruited) consisted of 4,191 students (53\% female, $47 \%$ male) who were mostly Caucasian $(81.7 \%)$, followed by African American (11.3\%), Hispanic (2.9\%), Asian (1.9\%), and other/unreported $(0.8 \%)$. Auburn University's 2008 incoming freshman class (from which the subjects of the second cohort were recruited) consisted of 3,984 students (52\% female, $48 \%$ male) who were mostly Caucasian $(88.1 \%)$, followed by African American (5.6\%), Hispanic (2.4\%), Asian $(1.9 \%)$, and other/unreported $(2 \%)$. The majority of the students in both incoming classes were from the state of Alabama (over 65\%) followed by Georgia (about 13\%) among other states.

This study was part of a larger, longitudinal study also assessing psychosocial traits and selected lifestyle habits. Physical activity was assessed using a subsample of questions based on the National College Health Risk Behavior Survey [31]. Physical activity questions included: (1) How many days per week do you participate in vigorous physical activity? (Vigorous activities are those that cause you to sweat and breathe hard.); (2) How many days per week do you participate in moderate physical activity? (Moderate activities include, for example, walking or bicycling); (3) How many days per week do you participate in strengthening exercises? (Strengthening exercises include activities such as push-ups, sit-ups, or weight lifting). Immediately following each question regarding vigorous, moderate, and strengthening exercises, participants were asked to specify the number of minutes per day spent in each activity.

\section{Statistical Methods}

Statistical analyses were performed using the software InStat version 3.0 (GraphPad Software, San Diego, CA). Descriptive statistics were computed for all variables. Chi square tests were used to examine differences between each study population (cohorts 1 and 2) and the university's incoming freshman classes (2007 and 2008), respectively. Differences in the outcome measures (body weight, BMI, percent body fat, fat mass, fat free mass, and waist circumference, moderate physical activity, vigorous physical activity, and strength training) between cohorts 1 and 2 were examined using unpaired t-tests and analysis of variance (ANOVA). Repeated measures ANOVA was used to examine differences in outcome measures at the beginning of fall, end of spring, and beginning of next fall and to examine differences between academic year and summer periods in absolute changes and rate of changes in outcome measures. The rate of change for each outcome measure was calculated by dividing the measure's change by the time period between visits. ANOVA was used to determine differences in summer weight change among participants based on end of the academic year BMI (underweight, normal weight, overweight/obese). ANOVA was also used to determine differences in BMI between participants and dropouts (both those that dropped out after fall semester and those that dropped out after spring semester). Statistically significant findings using ANOVA were followed by Tukey's multiple compari- 
sons test. Unpaired t-tests were used to determine differences in summer weight change between students who had gained weight versus lost over the academic year. Pearson correlation was used to examine relationships between weight change and waist change. A p-value less than 0.05 indicated statistically significant findings.

\section{RESULTS}

A group of 156 females volunteered for the study at the start of the fall semester 2007 (cohort 1) and 191 females volunteered for the study at the start of fall semester 2008 (cohort 2). Neither cohort 1 nor 2 significantly differed from the university's respective 2007 and 2008 freshman population suggesting a representative study sample. Of the 156 cohort 1 female participants 112 returned (72\%), and of the 191 cohort 2 female participants 125 returned (65\%) for assessments at the end of spring semester and the beginning of the next fall semester. Table $\mathbf{1}$ provides information on participant characteristics. No significant differences were found in initial body weight, BMI, and waist measurements or in changes in fat mass and percent body fat between cohorts 1 and 2. However, initial body composition measurements and changes in fat free mass and waist circumference slightly but significantly differed between the cohorts. Thus, data from the cohorts were analyzed both separately and combined.

Analysis of the initial ages (data not shown) and BMIs of the dropouts versus those of the participants produced no significant differences. After the initial fall and end of spring assessments, dropouts had average BMIs of $22.9 \pm 4.1 \mathrm{~kg} / \mathrm{m}^{2}$ and $22.3 \pm 3.3 \mathrm{~kg} / \mathrm{m}^{2}$, respectively. The average initial BMI of the participants who completed the study was $22.0 \pm 3.5$ $\mathrm{kg} / \mathrm{m}^{2}$.

Table 1 Age, Race, and Housing Characteristics of Participants who Completed the Study

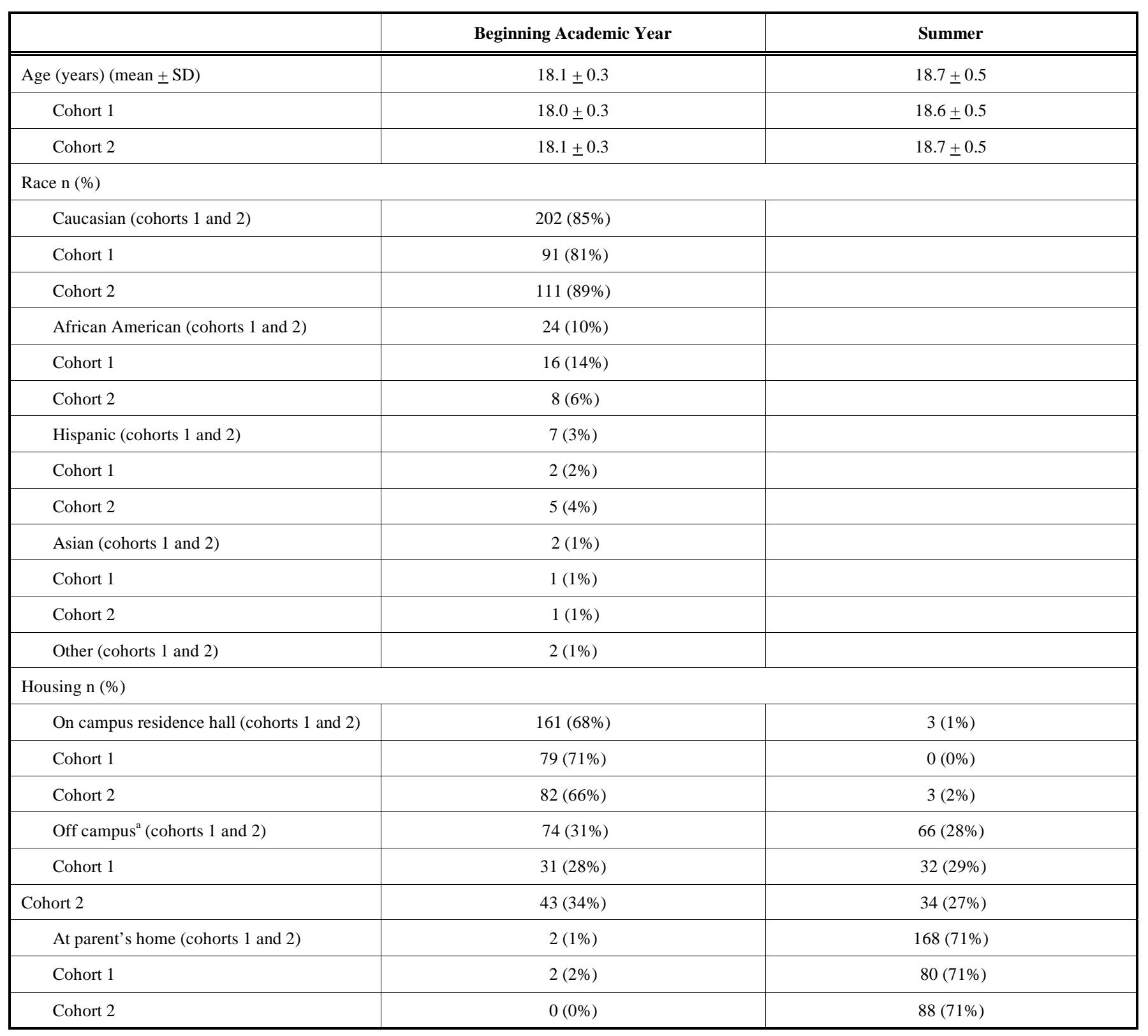

${ }^{a}$ Off campus housing includes: apartment, trailer, or house. 


\section{Anthropometric and Physical Activity Findings for the Academic Year and Summer}

Table 2 provides information on body weight, BMI, percent body fat, fat mass, fat free mass, and waist circumference at the start of the freshman academic year, at the end of the freshman academic year, and at the beginning of the sophomore year. Changes in these outcome measures for the academic year versus the summer are also shown. Significant gains in each of the outcome measures were found between the beginning and the end of the academic year, but not between the end of the academic year and the beginning of the sophomore year (i.e. over the summer) with three exceptions. Percent body fat for cohort 1 increased significantly during both the academic year and the summer, whereas fat free mass and waist circumference for cohort 1 did not significantly differ during the academic year or over the summer (Table 2).

Academic year weight gain for the entire group averaged $1.4 \pm 3.0 \mathrm{~kg}$, with a range of -9.3 to ${ }^{+} 13.6 \mathrm{~kg}$; summer weight change for the entire group averaged $-0.1 \pm 1.7 \mathrm{~kg}$, with a range of -6.8 to ${ }^{+} 4.7 \mathrm{~kg}$. Weight change did not significantly differ by race (data not shown). The rate of weight gain over the academic year $(0.16 \mathrm{~kg} /$ month) was significantly ( $\mathrm{p}<$ $0.0001)$ greater than the rate of weight change over the summer $(-0.02 \mathrm{~kg} / \mathrm{month})$.

Over the freshman academic year, both cohorts 1 and 2 had greater changes in weight, percent body fat, fat mass, and waist circumference than over the summer (Table 2).

Table 2. Body Weight, Body Mass Index (BMI), Body Composition, and Waist Circumference Findings (Mean \pm SD) of College Females at the Beginning and End of the Freshman Year and the Summer After the Freshman Year (Start of Sophomore Academic Year)

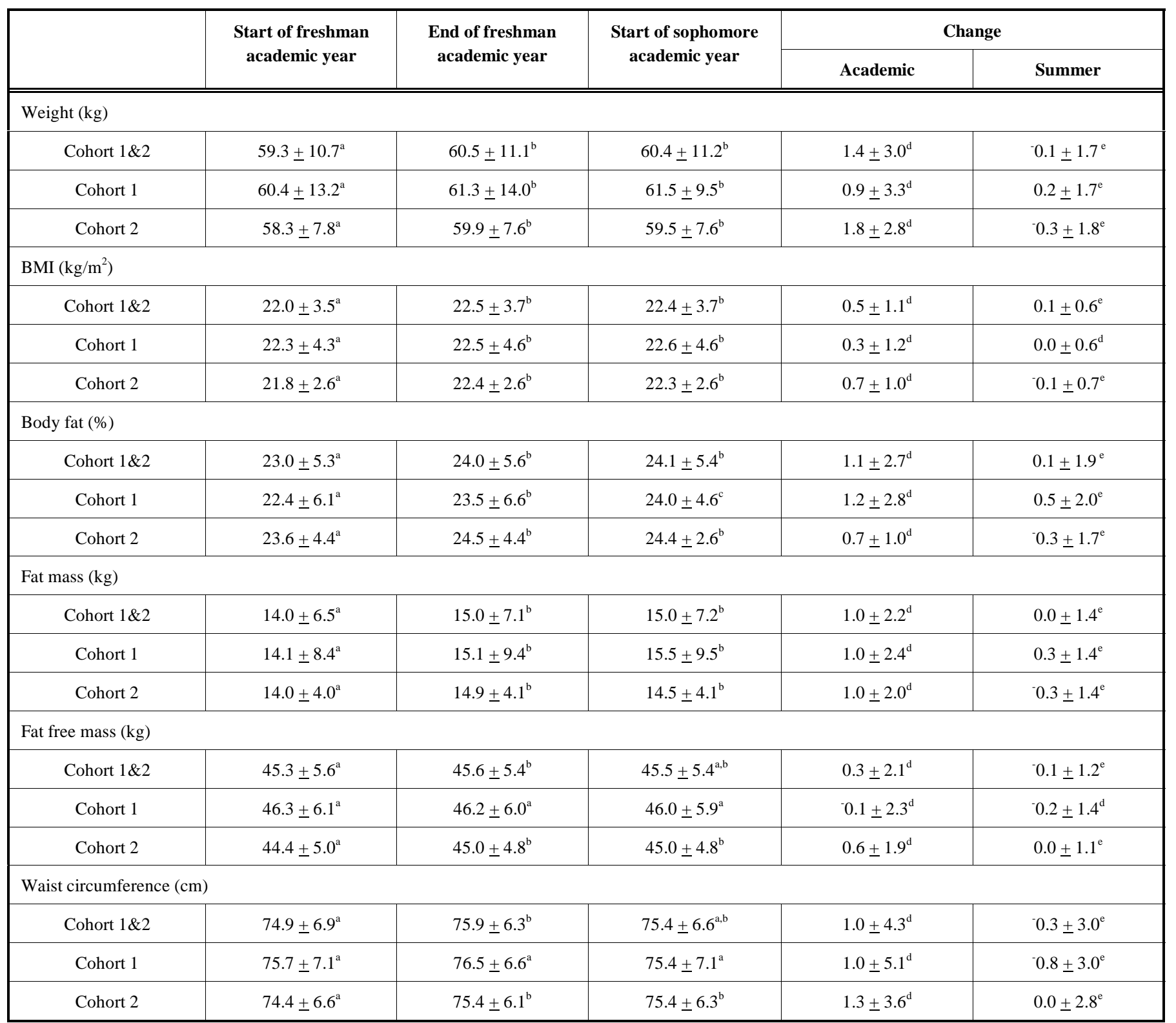

${ }^{a, b, c}$ Rows with different letters differ statistically significantly for the academic year.

${ }^{\mathrm{d}, \mathrm{e}}$ Rows with different letters differ statistically significantly between the change over the academic year versus the change over the summer. 
The change (gain) in BMI and fat free mass over the academic year was also significantly greater than that over the summer for the group but primarily due to cohort 2 . The gain in fat mass $(1.1 \pm 2.3 \mathrm{~kg})$ was significantly $(\mathrm{p}<0.001)$ greater than the gain in fat free mass $(0.2 \pm 2.0 \mathrm{~kg})$ for the combined academic year plus summer. Change in waist circumference was significantly $(\mathrm{p}<0.001)$ correlated with change in weight for both the academic year $(r=0.5761)$ and the summer $(\mathrm{r}=0.4657)$.

Over the freshman academic year, time spent engaging in vigorous physical activity did not significantly differ between cohort $1(115 \pm 106$ minutes/week) and cohort 2 (116 \pm 108 minutes/week); however time spent engaging in moderate physical activity was significantly $(\mathrm{p}<0.0001)$ greater for cohort 1 (239 \pm 127 minutes/week) versus cohort 2 (177 \pm 133 minutes/week). During the summer, time spent engag- ing in vigorous physical activity also did not significantly differ between cohort $1(100 \pm 94$ minutes/week) and cohort 2 (95 \pm 96 minutes/week). However, the reverse was found for time spent engaging in moderate physical activity, whereby cohort 1 spent significantly $(\mathrm{p}<0.0001)$ less time $(111 \pm 81 \mathrm{minutes} / \mathrm{week})$ than cohort $2(144 \pm 125 \mathrm{~min}-$ utes/week). The average time both cohorts spent engaging in vigorous physical activity was significantly $(\mathrm{p}=0.006)$ greater during the academic year $(119 \pm 106$ minutes/week $)$ versus the summer $(98 \pm 99$ minutes/week). Similarly, the average time both cohorts spent engaging in moderate physical activity was significantly ( $<<0.0001)$ greater during the academic year $(206 \pm 137$ minutes/week) versus the summer $(138 \pm 118$ minutes/week). This same trend between the academic year and the summer was observed for each cohort independently (data not shown).

Table 3. Monthly Rate of Change in Body Weight, Body Mass Index (BMI), Body Composition, and Waist Circumference (Mean \pm SD) of College Females Over the Academic Freshman Year and the Summer after the Freshman Year

\begin{tabular}{|c|c|c|}
\hline & \multicolumn{2}{|c|}{ Rate of Change / Month } \\
\hline & Academic & Summer \\
\hline \multicolumn{3}{|l|}{ Weight (kg/month) } \\
\hline Cohorts $1 \& 2$ & $0.16 \pm 0.37^{\mathrm{a}}$ & $-0.02 \pm 0.45^{\mathrm{b}}$ \\
\hline Cohort 1 & $0.10 \pm 0.38^{\mathrm{a}}$ & $0.05 \pm 0.43^{\mathrm{a}}$ \\
\hline Cohort 2 & $0.21 \pm 0.36^{\mathrm{a}}$ & $0.06 \pm 0.46^{\mathrm{b}}$ \\
\hline \multicolumn{3}{|c|}{ BMI (kg/m²/month) } \\
\hline Cohorts $1 \& 2$ & $0.06 \pm 0.14^{\mathrm{a}}$ & $0.01 \pm 0.17^{\mathrm{b}}$ \\
\hline Cohort 1 & $0.03 \pm 0.14^{\mathrm{a}}$ & $0.01 \pm 0.16^{\mathrm{a}}$ \\
\hline Cohort 2 & $0.07 \pm 0.13^{\mathrm{a}}$ & $0.03 \pm 0.17^{\mathrm{b}}$ \\
\hline \multicolumn{3}{|c|}{ Body fat (\%/month) } \\
\hline Cohorts $1 \& 2$ & $0.14 \pm 0.33^{\mathrm{a}}$ & $0.01 \pm 0.49^{b}$ \\
\hline Cohort 1 & $0.14 \pm 0.35^{\mathrm{a}}$ & $0.16 \pm 0.54^{\mathrm{a}}$ \\
\hline Cohort 2 & $0.13 \pm 0.31^{\mathrm{a}}$ & $0.07 \pm 0.43^{b}$ \\
\hline \multicolumn{3}{|c|}{ Fat mass (kg/month) } \\
\hline Cohorts $1 \& 2$ & $0.13 \pm 0.26^{\mathrm{a}}$ & $0.01 \pm 0.36^{\mathrm{b}}$ \\
\hline Cohort 1 & $0.11 \pm 0.27^{\mathrm{a}}$ & $0.10 \pm 0.36^{\mathrm{a}}$ \\
\hline Cohort 2 & $0.14 \pm 0.26^{\mathrm{a}}$ & $0.05 \pm 0.36^{\mathrm{b}}$ \\
\hline \multicolumn{3}{|c|}{ Fat free mass (kg/month) } \\
\hline Cohorts $1 \& 2$ & $0.04 \pm 0.25^{\mathrm{a}}$ & $0.02 \pm 0.30^{\mathrm{b}}$ \\
\hline Cohort 1 & $0.01 \pm 0.27^{\mathrm{a}}$ & $0.05 \pm 0.34^{\mathrm{a}}$ \\
\hline Cohort 2 & $0.07 \pm 0.23^{\mathrm{a}}$ & $0.01 \pm 0.27^{\mathrm{b}}$ \\
\hline \multicolumn{3}{|c|}{ Waist circumference $(\mathrm{cm} / \mathrm{month})$} \\
\hline Cohorts $1 \& 2$ & $0.13 \pm 0.52^{\mathrm{a}}$ & $0.10 \pm 0.78^{b}$ \\
\hline Cohort 1 & $0.12 \pm 0.65^{\mathrm{a}}$ & $0.27 \pm 0.72^{b}$ \\
\hline Cohort 2 & $0.13 \pm 0.41^{\mathrm{a}}$ & $0.00 \pm 0.80^{\mathrm{a}}$ \\
\hline
\end{tabular}

${ }^{a, b}$ Rows with different letters differ statistically significantly. 


\section{Anthropometric Findings: Rate of Change for the Aca- demic Year and Summer}

Greater rates of changes for body weight and composition (but not waist circumference) were found for the academic year versus the summer for cohort 2 (Table 3). No differences were found in the rates of changes for these outcome measures (except waist circumference) between the two time periods for cohort 1 (Table $\mathbf{3}$ ).

\section{Anthropometric Summer Findings Based on Academic Year Weight Change and BMI}

Over the summer, 119 participants $(50 \%)$ lost or stayed the same weight $(-1.3 \pm 1.3 \mathrm{~kg})$ and 118 participants $(50 \%)$ gained weight $(1.2 \pm 1.0 \mathrm{~kg})$. Summer weight change differed significantly $(\mathrm{p}=0.0059)$ between participants who gained weight over the academic year versus those who had lost weight over the academic year. Over the academic year, 162 participants (68\%) gained weight, an average of $2.8 \pm$ $2.3 \mathrm{~kg}$, but this group lost only $-0.3 \pm 1.7 \mathrm{~kg}$ over the summer. Over the academic year, 75 participants (32\%) lost weight or stayed the same weight, an average of $-1.7 \pm 2.0$ $\mathrm{kg}$; over the summer this group gained $0.4 \pm 1.7 \mathrm{~kg}$. Summer weight change did not significantly differ among underweight participants $(n=23$; with an end of spring semester BMI $<18.5 \mathrm{~kg} / \mathrm{m}^{2}$ ) with an average weight loss of $0.03 \pm$ $1.59 \mathrm{~kg}$ versus normal weight participants $(\mathrm{n}=181$; with an end of spring semester BMI $18.5-24.9 \mathrm{~kg} / \mathrm{m}^{2}$ ) with an average weight loss of $0.02 \pm 1.69 \mathrm{~kg}$ versus overweight/obese participants $(n=33$; with an end of spring semester BMI $>25$ $\mathrm{kg} / \mathrm{m}^{2}$ ) with an average weight loss of $0.43 \pm 2.08 \mathrm{~kg}$.

\section{DISCUSSION}

Two objectives of this study were to examine changes and rates of changes in body weight, composition, and shape in college females between the freshman academic year and the summer after the freshman academic year. During the freshman academic year, significant increases in weight, BMI, body fat, and fat mass were observed in both cohorts. Both cohorts gained less or lost weight, BMI, percent body fat, fat mass, and waist circumference over the summer. Yet, while the general directions of change for both cohorts were similar, cohort 1 exhibited an average summer weight gain $(0.2 \mathrm{~kg})$ whereas cohort 2 exhibited an average summer weight loss $(-0.3 \mathrm{~kg})$. The changes observed in cohort 1 are similar to the findings by Hull and associates [29] who found that body weight increased $1.3 \mathrm{~kg}$ during the academic freshman year and another $0.1 \mathrm{~kg}$ during the summer in a group of 69 college females. However, in contrast to significant increases in fat mass over the year and decreases in fat mass over the summer in the females in Hull's study [29], both cohorts of females in the present study had gains or changes in percent body fat and fat mass that were significantly less in the summer versus the academic year. When examining the physical activity habits; the significantly greater amount of time engaged in moderate physical activity during the summer by cohort 2 likely contributed to the group's weight loss versus cohort 1 who gained weight and spent less time engaged in moderate physical activity during the summer. Similarly, over the academic year, the significantly greater amount of time engaged in moderate physical activity by cohort 1 likely contributed to the group's lower weight gain than cohort 2 who gained more weight and spent significantly less time engaged in moderate physical activity.

The significant decrease in physical activity between the academic year and the summer coupled with the significant decrease in the rate of change in weight, BMI, percent body fat, and fat mass for cohort 2 between the academic year and the summer supports the likelihood of healthier dietary behaviors in the summer. Never-the-less, the absolute gains in weight, fat mass, and percent body fat by cohort 1 during the summer (even though they were less than what was gained over the academic year) and the lack of a significant difference between the academic year and summer in the rates of change for weight and body composition are worrisome.

Some weight gain during college is expected. Height-forage growth curves for females suggest gains in height cease between about 18 to 20 years, with increases in height after age 16 years being generally quite minimal [32]. Yet, while weight gain typically occurs with height gains, with the cessation of growth, excessive weight gain can be detrimental to health. Obesity is a known risk factor for type 2 diabetes mellitus, heart disease, osteoarthritis, and some cancers, among other problems.

The college years have been suggested as a critical period for weight gain for young adults $[6,29]$. While many studies have reported weight gain, especially in females, during the freshman year, only a few studies have examined weight change in college students beyond the freshman year $[26,28,29,33,34]$. Notable findings from some of these studies $[26,33]$ include the slowed rate of weight gain in females between the freshman and sophomore years of college. This result was also shown in Hull's study [29] that examined changes the summer after the freshman year $(0.21 \mathrm{~kg} / \mathrm{month}$ rate of weight gain during the academic year versus 0.0 $\mathrm{kg} /$ month during the summer), and in the present study (rate of weight change of $0.16 \mathrm{~kg} /$ month during the academic year to $-0.02 \mathrm{~kg} /$ month over the summer). Yet, these reported academic year rates of weight gain for the college freshmen exceed those reported for young women as part of the Cardia study [3].

The inclusion of waist circumference, a unique addition to this study, provides additional evidence suggesting increased health risks. Waist circumference significantly increased over the academic year in cohort 2 , and in both cohorts the academic year change in waist circumference was significantly greater than the summer change. While cohort 1 showed a slight but significant decrease in waist circumference over the summer suggesting perhaps healthier changes in dietary habits, weight change was significantly and positively correlated with waist circumference change. Waist circumference is thought to be one of the best indicators of obesity-related health risks including type 2 diabetes and heart disease [35-39]. The overall absolute net increases in waist circumference coupled with the overall increases in percent body fat and fat mass observed in this study suggest unfavorable changes in body shape as well as body composition in female college freshmen, and help support the notion that the college years are a critical period for not only weight gain but also undesirable body composition changes.

Two other objectives of this study were to determine if participants either lost weight that was gained or gained 
weight that was lost over the academic year, and to determine differences in summer weight change based on end of the academic year BMI. The assumption was that those who gained weight over the academic year would lose the excess weight over the summer. Yet, while summer weight loss was significantly greater in the academic year weight gain group than in the academic year weight loss group, neither group completely returned to their initial weight. The academic year weight gain group exhibited a net yearly gain of $2.5 \mathrm{~kg}$ and the academic year weight loss group exhibited a net yearly loss of $-1.3 \mathrm{~kg}$. These findings suggest that summer weight loss efforts were partially successful by some of the females who had gained weight over the academic year and that summer weight gain efforts were successful for at least some of the females who had lost weight over the academic year. The fact that no significant differences in summer weight change were found among participants who were underweight, normal weight, or overweight/obese at the start of the summer may be the result of the relatively few numbers of females in the underweight or overweight/obese categories versus normal weight category. Further, weight change efforts were not included in the analyses and could influence study findings.

Studies examining weight changes after the freshman year are few $[26,28,33,34]$ and have not investigated weight change based on BMI or freshman year changes. Variable changes in weight have been documented after the freshman year. Racette and coworkers [28], for example, found that college students $(n=290)$ gained about $4.1 \mathrm{~kg}(9 \mathrm{lbs})$ between the beginning of the freshman year and the end of the sophomore year, but did not look at the changes between the two years individually. In a follow-up study and only one examining four years, weight gain from the freshman to senior year of 138 college females averaged less than $1.7 \mathrm{~kg}$ (3.75 lbs) [33].

The results of the present study provide an important contribution characterizing changes in weight, body composition, and body shape (waist circumference) among female college students with a range of BMIs after the freshman year. While the changes in outcome measures were generally more favorable for health over the summer versus the academic year, the net gains in weight, percent body fat, fat mass, and waist circumference suggest interventions are needed. Reasons for the observed differences in changes in weight and body composition between cohorts 1 and 2 are related in part to differences in moderate physical activity habits; however, further studies are needed to more closely examine dietary, exercise, and lifestyle habits of college students and barriers to healthful living. It has been suggested that college students lack adequate self-regulatory skills, including planning and self-monitoring, to maintain healthful behaviors [40].

The findings of the present study should be interpreted with caution as self-selection bias may have occurred; it is possible that only those students who felt secure with their weight or were comfortable enough to be measured returned. In addition, a loss of participants is of concern and could affect the generalizability of the study's findings; however, no statistically significant differences were found in BMI or age between those who completed the study and those who dropped out. A further limitation is that participants in this study attended a major public university in the South, thus, the results may not be applicable to students attending private universities or universities in other parts of the country. Lastly, weight goals of the participants were not controlled for and may have influenced the results.

\section{CONCLUSIONS}

The findings of this study showed that summer does not reverse weight gained over the freshman year for most college females. Weight gain was accompanied by gains in percent body fat, fat mass, and waist circumference. Should these trends continue into the sophomore, junior, and senior years of college, more young adults could be classified as overweight or obese in their early to mid-twenties and could be at an increased risk of disease.

\section{CONFLICT OF INTEREST}

The authors declare that they have no competing or conflict of interest.

\section{ACKNOWLEDGEMENTS}

The authors would like to thank Catie Dobbs, Paul Harrington, Meghan Benak, and Jenna McClure for their help with data collection and Dr. B. Douglas White for assistance with some statistical analyses. This research was funded by U.S.D.A. AL Agricultural Experiment Station (AAES) projects 013-020 and 07-020, and an AAES Initiative Grant.

\section{REFERENCES}

[1] Ogden CL, Carroll MD, Curtin LR, McDowell MA, Tabak CJ Flegal KM. Prevalence of overweight and obesity in the United States, 1999-2004. JAMA 2006; 295:1549-55.

[2] Centers for Disease Control and Prevention: Behavioral Risk Factor Surveillance System Survey Data. Atlanta, Georgia: U.S. Department of Health and Human Services, Centers for Disease Control and Prevention, 2007.

[3] Lewis CE, Jacobs DR, McCreath $\mathrm{H}$, et al. Weight gain continues in the 1990s: 10-year trends in weight and overweight from the CARDIA study. Am J Epidemiol 2000; 151: 1172-81.

[4] Burke GL, Bild DE, Hilner JE, Folsom AR, Wagenknecht LE, Sidney S. Differences in weight gain in relation to race, gender, age, and education in young adults: The CARDIA Study. Ethn Health 1996; 1: 327-35.

[5] Mokdad AH, Serdula MK, Dietz WH, Bowman BA, Marks JS, Koplan JP. The spread of the obesity epidemic in the United States, 1991-1998. JAMA 1999; 282: 1519-22.

[6] Anderson DA, Shapiro JR, Lundgren JD. The freshman year of college as a critical period for weight gain: an initial evaluation. Eat Behav 2003; 4: 363-7.

[7] Butler SM, Black DR, Blue CL, Gretebeck RJ. Change in diet, physical activity and body weight in female college freshman. Am J Health Behav 2004; 28: 24-32.

[8] Crombie AP, Ilich JZ, Dutton GR, Panton LB, Abood DA. The freshman weight gain phenomenon revisited. Nutr Rev 2009; 67: 83-94.

[9] Delinsky SS, Wilson GT. Weight gain, dietary residency, and disordered eating in the freshman year of college. Eat Behav 2008; 9: 82-90.

[10] Economos CD, Hildebrandt ML, Hyatt RR. College freshman stress and weight change: differences by gender. Am J Health Behav 2008; 32: 16-25.

[11] Graham MA, Jones AL. Freshman 15: valid theory or harmful myth?. J Am Coll Health 2002; 50: 171-3.

[12] Gropper SS, Drawdy K, Gaines A, et al. It's not the freshmen 15 [abstract]. FASEB J 2008; 22: 678.

[13] Gropper SS, Simmons K, Gaines A, et al. The freshman 15 - a closer look. J Am Coll Health 2009; 58: 223-31.

[14] Hajhosseini L, Holmes T, Mohamadi P, Goudarzi V, McProud L, Hollenbeck CB. Changes in body weight, body composition and 
resting metabolic rate (RMR) in first-year university freshmen students. J Am Coll Nutr 2006; 25: 123-7.

[15] Hodge CN, Jackson LA, Sullivan L. The "Freshman 15" Facts and fantasies about weight gain in college women. Psychol Women Q 1993; 17: 119-26.

[16] Hoffman DJ, Policastro P, Quick V, Soo-Kyung L. Changes in body weight and fat mass of men and women in the first year of college: a study of the "freshman 15". J Am Coll Health 2006; 55: 41-45.

[17] Holm-Denoma JM, Joiner TE, Vohs KD, Heatherton TF. The freshman fifteen (the freshman five actually): predictors and possible explanations. Health Psychol 2008; 27(1 Suppl): S3-S9.

[18] Jung ME, Bray SR, Ginis KAM. Behavior change and the freshman 15: tracking physical activity and dietary patterns in $1_{\text {st-year }}$ university women. J Am Coll Health 2008; 56: 523-30.

[19] Kasparek DG, Corwin SJ, Valois RF, Sargent RG, Morris RL. Selected health behaviors that influence college freshman weight change. J Am Coll Health 2008; 56: 437-44.

[20] Levitsky DA, Halbmaier CA, Mrdjenovic G. The freshman weight gain: a model for the study of the epidemic of obesity. Int J Obesity 2004; 28: 1435-42.

[21] Lowe MR, Annunziato RA, Markowitz JT, et al. Multiple types of dieting prospectively predict weight gain during the freshman year of college. Appetite 2006; 47: 83-90.

[22] Megal ME, Hawkins P, Sandstrom S, Hoefler MA, Willrett K. Health promotion, self-esteem, and weight among female college freshmen. Health Values 1994; 18: 10-9.

[23] Mihalopoulos NL, Auinger P, Klein JD. The freshman 15: is it real? J Am Coll Health 2008; 56: 531-4.

[24] Morrow ML, Heesch KC, Dinger MK, Hull HR, Kneehans AW, Fields DA. Freshman 15: fact or fiction. Obesity 2006; 14: 143843.

[25] Pilner P, Saunders T. Vulnerability to freshman weight gain as a function of dietary restraint and residence. Physiol Behav 2008; 93 : 76-82.

[26] Hovell MF, Mewborn CR, Randle Y, Fowler-Johnson S. Risk of excess weight gain in university women: a three-year community controlled analysis. Addict Behav 1985; 10: 15-28.

[27] Serlachius A, Hammer M, Wardle J. Stress and weight change in university students in the United Kingdom. Physiol Behav 2007; 92: 548-53.

[28] Racette SB, Deusinger SS, Strube MJ, Highstein GR, Deusinger RH. Weight changes, exercise, and dietary patterns during fresh- man and sophomore years of college. J Am Coll Health 2005; 53: 245-51.

[29] Hull HR, Morrow ML, Heesch KC, Dinger MK, Han JL, Fields DA. Effect of summer months on body weight and composition in college women. J Women's Health 2007; 16: 1510-5.

[30] Nelson MC, Kocos R, Lytle LA, Perry CL. Understanding the perceived determinants of weight-related behaviors in late adolescence: A qualitative analysis among college youth. J Nutr Educ Behav 2009; 41: 287-92.

[31] Center for Disease Control and Prevention (CDC). National College Health Risk Behavior Survey. http://www.cdc.gov/Healthy Youth/yrbs/data/college/nchrbs95.pdf [Accessed 2/2/2006].

[32] Center for Disease Control and Prevention (CDC). Growth Charts. www.cdc.gov/growthcharts. [Accessed 2/22/2009].

[33] Racette SB, Deusinger SS, Strube MJ, Highstein GR, Deusinger RH. Changes in weight and health behaviors from freshman through senior year of college. J Nutr Educ Behav 2008; 40: 39-42.

[34] Hull HR, Morrow ML, Dinger MK, Han JL, Fields DA. Characterization of body weight and composition changes during the sophomore year of college. BMC Women's Health 2007; 7: 21-8.

[35] Janssen I, Katzmarzyk PT, Ross R. Waist circumference and not body mass index explains obesity-related health risk. Am J Clin Nutr 2004; 79: 379-84

[36] Farajian P, Renti E, Manios Y. Obesity indices in relation to cardiovascular disease risk factors among young adult female students. Br J Nutr 2008; 99: 918-24.

[37] Seidell JC, Perusse L, Despres J, Bouchard C. Waist and hip circumferences have independent and opposite effects on cardiovascular disease risk factors: the Quebec family study. Am J Clin Nutr 2001; 74: 315-21.

[38] Ho SC, Chen YM, Woo JLF, Leung SSF, Lam TH, Janus ED Association between simple anthropometric indices and cardiovascular risk factors. Int J Obesity 2001; 25: 1689-97.

[39] Dobbelsteyn CJ, Joffres MR, MacLean DR, Flowerdew G. Canadian Heart Health Surveys Research Group. A comparative evaluation of waist circumference, waist-to-hip ratio, and body mass index as indicators of cardiovascular risk factors. The Canadian Heart Health Surveys. Int J Obesity 2001; 25: 652-61.

[40] Strong KA, Parks SL, Anderson E, Winett R, Davy BM. Weight gain prevention: identifying theory-based targets for health behavior change in young adults. J Am Diet Assoc 2008; 108: 1708- 15.

Received: February 27, 2010

Revised: June 07, 2011

Accepted: June 18, 2011

(C) Gropper et al.; Licensee Bentham Open

This is an open access article licensed under the terms of the Creative Commons Attribution Non-Commercial License (http://creativecommons.org/licenses/by-nc/3.0/) which permits unrestricted, non-commercial use, distribution and reproduction in any medium, provided the work is properly cited. 